\title{
Pontes sobre o nada: narrativas do sofrimento e transformação existencial
}

\section{Bridges over nothingness: narratives of suffering and existential transformation}

\author{
Prof. Dr. Marco Casanova ${ }^{1}$ \\ Professor Associado do Departamento de Filosofia da Universidade Estadual do Rio de \\ Janeiro \\ E-mail: casanovamarco_271@hotmail.com
}

Resumo: o principal intuito do presente artigo é questionar uma tendência estrutural de nosso modo tradicional de compreensão do problema da negatividade. Se considerarmos a reação imediata à afirmação de que a existência se caracteriza exatamente como uma indeterminação ontológica radical, não é incomum perceber a dificuldade de assumir essa afirmação sem uma certa sensação de que inviabiliza por completo a própria existência, caso não seja contrabalanceada por alguma dimensão de soterramento da nadidade, de pavimentação da negatividade. Tal dificuldade repercute sobre os modos mais imediatos de lidar com o sofrimento existencial e mesmo de pensar o foco mais essencial das terapias em geral. Na medida em que questionamos esses modos e seus pressupostos mais imediatos, o que buscamos aqui é antes de tudo investigar até que ponto o problema mais intrínseco do sofrimento reside precisamente na carga imensa que provém justamente da tentativa de fugir dele. Heidegger é, nesse contexto, nosso parceiro mais próximo de diálogo, assim como a metáfora da ponte e do farol que nos guia incessantemente em nosso caminho.

Palavras-chave: Heidegger; Negatividade; Sofrimento existencial.

Abstract: the central aim of the present article is to put in question a structural tendency of our tradition of understanding the problem of negativity. If we consider the immediate reaction to the assertion that existence characterizes itself exactly through a very

\footnotetext{
1 Possui graduação em Letras Português Literatura pela Universidade do Estado do Rio de Janeiro(1990), graduação em Filosofia pela Universidade Federal do Rio de Janeiro(1991), mestrado em Filosofia pela Universidade Federal do Rio de Janeiro(1993), doutorado em Filosofia pela Universidade Federal do Rio de Janeiro(1999), pós-doutorado pela Universität Freiburg(2006) e pós-doutorado pela Universität Freiburg(2006). Atualmente é Professor Adjunto da Universidade do Estado do Rio de Janeiro, Membro de corpo editorial da Natureza Humana, Revisor de periódico da Natureza Humana, Membro de corpo editorial da Ekstasis: Revista de Hermenêutica e Fenomenologia, Revisor de projeto de fomento do Coordenação de Aperfeiçoamento de Pessoal de Nível Superior, Revisor de projeto de fomento do Fundação Carlos Chagas Filho de Amparo à Pesquisa do Estado do RJ, Membro de corpo editorial da Revista Princípios, Revisor de periódico da Revista Princípios e Revisor de periódico da Ekstasis - Revista eletrônica do programa de pósgraduação em filosofia da. Tem experiência na área de Filosofia, com ênfase em Metafísica. Atuando principalmente nos seguintes temas:Vida - História - Valor. Informações coletadas do Lattes em 31/10/2019
} 
ontological indeterminacy, it is not uncommon to perceive how hard is to embrace this assertion without a sensation that it makes impossible the own existence, if it is not counterbalanced by any kind of attenuation to such a nothingness, of paving negativity. Such difficulty resonates over the main ways to cope with existential suffering and even of thinking the most essential focus of therapies in general. Putting in question these ways of thinking and their presupposes, we are trying over all to investigate if suffering itself has its basis in the extraordinary weight arousing from the proper attempt to avoid suffering. Heidegger is, in this context, our closer partner of dialog, such as the metaphors of the bridge and the lighthouse which guide us in our path.

Keywords: Heidegger; Negativity; Existential suffering.

Eu escrevi no início da primeira edição de $O$ culpado essas palavras, cujo sentido respondia (em seu conjunto) à impressão que eu tinha de habitar - nós estávamos em 1942 - um mundo onde estava na situação de um estrangeiro. (Em certo sentido, essa situação não me surpreendia: os sonhos de Kafka, de diversas maneiras, são mais frequentes do que nós pensamos o fundo das coisas...). Georges Bataille, Le Coupable.

Por certo, cada vez mais seriamente se evidencia que o filosofar, apesar de acontecer na essência do ser-aí, sim, exatamente porque acontece aí e somente aí, carece de uma libertação, junto à qual o ser-aí precisa usar de violência contra si mesmo. Toda violência, porém, encerra dor em si. Martin Heidegger, Introdução à filosofia.

Logo que nos aproximamos do tema do sofrimento, todo um conjunto de posições prévias, a princípio inquestionadas, vem à tona imediatamente. Não há como ouvirmos a palavra "sofrimento" sem que venha acompanhada de uma série de afirmações correlatas. Para nós, o sofrimento, por trazer consigo dor física ou psíquica, precisa ser sempre tratado com vistas à sua eliminação o mais prontamente possível; carece invariavelmente de compreensão e cura; ele torna evidente o quanto devemos sempre buscar formas preventivas de lidar com seu aparecimento incessantemente possível, assim como precisamos desenvolver estratégias para não sucumbirmos nos momentos de sua inexorável aparição.

Tratamento, compreensão, cura, prevenção, descoberta de medidas paliativas. Todas essas palavras confluem para uma pressuposição fundamental: a de que o sofrimento é ruim e precisa ser dissipado sempre que possível ou, no pior dos casos, enfraquecido em seu potencial destrutivo. A própria etimologia da palavra sofrimento revela o quanto o seu contexto originário está já impregnado por tal pressuposição. $\mathrm{O}$ termo vem do latim, sufferre, que significa literalmente "estar sob ferros". Ela designava outrora a situação dos escravos acorrentados, que não podiam escapar das dores que lhes 
eram infringidas e que, consequentemente, estavam condenados a elas. Sofrer significa, assim, originariamente, estar sob o peso do ferro, se ver aprisionado, escravizado pela dor, perder radicalmente sua liberdade e experimentar necessariamente uma restrição, uma privação em suas possibilidades mesmas de ser. Sofrer é experiência restritiva, privativa, senão mesmo destrutiva e fragmentadora.

É exatamente por isso que a essa posição prévia do problema corresponde todo um conjunto de elementos que possuem lugares específicos já de antemão demarcados no próprio campo de manifestação do sofrimento. Temos aqui uma característica estrutural de um modo hermenêutico e fenomenológico de consideração, o que em última instância equivale, por razões que não temos aqui como explicitar de maneira detida, a um modo rigoroso de tratamento dos problemas. O sofrimento não é uma realidade, que se encontraria dada de maneira subsistente no plano de nossas concepções pretensamente puras e de nossa capacidade correlata de identificar suas propriedades essenciais. Ao contrário, ele possui uma fenomenalidade própria, condições específicas de fenomenologização, que obedecem por princípio ao caráter histórico de seu campo.

Bem, mas a posição prévia do fenômeno do sofrimento envolve, como dissemos acima, a constituição de uma rede local, de um território demarcado em seus limites e hierarquias próprias. Não há sofrimento sem remédios, hospitais, profissionais de saúde, psicólogos, psiquiatras, padres, pastores, igrejas, curandeiros, mesmo filósofos. Toda a rede é constituída a partir de elementos particulares, com relações de centralidade e marginalidade, com determinações significativas que obedecem radicalmente à posição prévia na rede. Esse é um elemento para nós importante a princípio. A posição prévia de um problema encerra em si todo um conjunto de posições em um todo relacional. Nesse todo relacional, trabalha-se sempre em constelações, de tal modo que não se trata aqui de maneira alguma da ideia de que se teria blocos construtivos dotados de peculiaridades próprias identificáveis a priori, antes do campo de relações, e de que esses blocos comporiam a partir de tais determinações a figura do todo. Não! A posição prévia com a qual o campo hermenêutico se revela determina radicalmente o significado mesmo de tudo aquilo que particularmente vem ao nosso encontro no campo. À posição prévia do problema, então, corresponde um modo específico de recorte do campo.

Nos deparamos acima com um elemento chave de um modo hermenêuticofenomenológico de consideração dos problemas. Quando um fenômeno vem à tona, ele nunca é constituído por uma subjetividade capaz de posicioná-lo a partir de suas próprias categorias, conceitos ou representações em seu ser. Ao contrário, ele deve antes sua 
determinação própria ao campo mesmo, no interior do qual ele se mostra como o fenômeno que ele é. Tal campo, contudo, nunca é simplesmente um campo significativo específico, dotado de um nexo originário com o ser do fenômeno, mas se revela muito mais como um campo historicamente constituído, no qual constelações relacionais sedimentadas fazem com que o fenômeno emerja tal como ele é. Assim, uma coisa, um ser vivo, um homem ou um tema sempre aparecem para nós inicialmente em seu significado, em uma dimensão pré-reflexiva, a partir da rede de suas relações e de sua posição em tal rede. Foi isso que vimos acima. Sofrimento, por exemplo, possui uma correlação originária com clínica, medicamento, disfunção, hospital, igreja, consultório psiquiátrico ou psicológico etc.; e seu significado provém justamente desse campo e de sua posição no campo. Mas nós nunca permanecemos unicamente diante de uma constelação relacional previamente sedimentada e historicamente constituída. Nós sempre vemos o que desponta na rede em função dos modos como os fenômenos se dão a princípio a ver. Dizer isso é o mesmo que afirmar que a posição prévia de um fenômeno ou de uma constelação fenomênica é responsável pela estruturação do campo em termos significativos, mas ainda não é suficiente para definir modos de relação propriamente ditos.

No livro III da "República", por exemplo, Platão comenta a necessidade de uma alimentação simples na formação dos guerreiros, exatamente para evitar que uma dieta rica em variedade propicie o surgimento da desordem e da desmedida ${ }^{2}$. Ao fazer isso, ele

\footnotetext{
2 Platão, "República", Livro III: "Sócrates - E que diremos a respeito da alimentação? Os nossos homens são os atletas da maior das disputas, não é assim?/ Glauco - Sim./ Sócrates - É adequado para eles o regime dos atletas comuns?/ Glauco - Talvez./ Sócrates - Mas é um regime que dá demasiada margem ao sono e expõe a saúde a muitos perigos. Não vês que esses atletas passam a vida a dormir e que, sempre que se afastam um pouco do regime que lhes foi prescrito, contraem graves doenças?/ Glauco - Sim./ Sócrates É necessário um regime mais apurado para os nossos atletas guerreiros, para que se mantenham, como os cães, sempre alerta, vejam e ouçam com a maior acuidade e, embora mudando frequentemente de bebida e comida, conservem uma excelente saúde./ Glauco - Sou da mesma opinião./ Sócrates - Pois a melhor ginástica não é irmã da música simples de que falávamos há pouco?/ Glauco - Que queres dizer?/ Sócrates - Que uma boa ginástica é simples, principalmente quando se destina a guerreiros./ Glauco - E em que consiste ela?/ Sócrates - Pode-se aprendê-lo em Homero. Sabes que, quando faz os seus soldados comerem em campanha, não os farta de peixes, apesar de estarem próximos do mar, junto ao Helesponto, nem de carnes preparadas, mas apenas de carnes assadas, de preparação muito simples para os seus soldados; com efeito, é mais fácil assar diretamente no fogo do que levar consigo utensílios de cozinha./ Glauco - Sim, com certeza./ Sócrates - Não parece também que Homero se refira a temperos. Os outros atletas não sabem que para se manter em boa forma devem evitar tudo isso?/ Glauco - Sabem e evitam./ Sócrates - Se consideras os nossos preceitos acertados, com certeza não aprovas a mesa siracusana e os variados pratos da Sicília./ Glauco - Não./ Sócrates - Também não aprovarás que homens que devem manter-se em boa forma tenham por amante uma jovem de Corinto?/ Glauco - Não, por certo./ Sócrates - Nem que se entreguem às famosas delicias da pastelaria ática?/ Glauco - Naturalmente./ Sócrates - Se comparássemos uma tal alimentação e um tal regime à melopéia e ao canto em que entram todos os tons e todos os ritmos, julgo que faríamos uma comparação correta./ Glauco - Sem dúvida./ Sócrates - Aqui, a variedade gera a
} 
vê a alimentação previamente no campo da formação educacional propriamente dita do guerreiro, assim como de sua integração plena na cidade bela, boa e justa. Em nosso tempo, contudo, muito marcado em grande espectro por uma hiperestesia evidente, lidamos com os alimentos exclusivamente a partir do prazer que podem nos propiciar ou a partir de padrões médicos de saúde os quais controlam incessantemente nossos comportamentos corporais. Assim, tendemos todos a viver hoje muito em nome dos prazeres gastronômicos, de tal modo que nos parece, de imediato, um suplício abdicar do refinamento da boa cozinha. Isso constitui um modo prévio de ver os fenômenos em jogo no campo da alimentação, no sentido de que temos aqui um modo prévio de como eles se deixam ver em sua relação conosco. O mesmo vale para o problema do sofrimento. Não é apenas o campo do sofrimento que se acha previamente demarcado, delimitado, instituído em seus pontos, retas e planos, em seus centros e suas margens. Nós também vemos o sofrimento a princípio de uma forma determinada.

O sofrimento nos convoca a uma disposição de ajuda, de compaixão, de compreensão e acompanhamento, de tratamento e cura. Não se chega jamais a ver simplesmente de maneira pura alguém ou mesmo algum ser qualquer sofrendo, mas já sempre se olha para o sofrimento em meio a uma mobilidade de consternação e auxílio. É claro que é possível e mesmo frequentemente verificável a indiferença dos homens em relação ao sofrimento alheio. Toda uma série de nossas atividades humanas extremamente evoluídas convive, além disto, com o sofrimento animal. De qualquer forma, a indiferença e a crueldade aparecem nesse contexto como modos de relação que não subvertem, mas ratificam o dito acima: não passam de comportamentos divergentes a partir da medida estabelecida pela visão prévia. À posição prévia e à visão prévia do problema corresponde, por fim, a conceptualidade prévia.

Quando algo vem ao nosso encontro, todo o campo de sua manifestação tanto quanto o modo como ele se deixa ver se encontram já previamente demarcados. Dizer isso significa acentuar o quanto as manifestações dos entes em geral obedecem sempre a uma circularidade hermenêutica, à constituição histórica da fenomenalidade mesma e ao sentido que se conforma a partir de tal constituição. Não há jamais uma objetividade por si subsistente, que poderia ser acessada a partir de uma purificação de nossos modos de compreensão da temporalidade histórica que atravessa tudo o que se mostra. Também cabe, porém, ao modo mesmo de manifestabilidade dos fenômenos, formas discursivas

desordem e o desregramento; ali, provoca a doença. Ao contrário, a simplicidade na música torna a alma moderada e na ginástica, o corpo saudável”. 
de articulação de sua compreensibilidade, modos de fala que instituem os caminhos de compartilhamento de seu ser em um tempo determinado. Nós nos acostumamos, por exemplo, como bem o revela Susan Sonntag em seu livro "Diante da dor dos outros", a todo um espetáculo de dor e sofrimento que atravessa o mundo de imagens fotográficas, cinematográficas e televisivas, que não necessariamente nos torna mais sensíveis à dor, mas que antes nos dá uma falsa impressão de proximidade. E já falamos sobre esses sofrimentos de guerra no interior da linguagem jornalística, que procura justamente descrever os acontecimentos a partir de uma pretensa neutralidade informativa, a partir de um olhar que apenas acompanha sem interferir a dinâmica dos fatos - por mais que, claro, tal conceptualidade prévia não resista a uma mínima inserção crítica do olhar.

O sofrimento em sua dimensão existencial, por outro lado, tende a ser tratado como sofrimento psíquico, ou seja, como sofrimento interno, ligado a uma subjetividade pensada dinamicamente em sua estrutura neurofisiológica, na mesma medida em que vem sendo cada vez mais absorvido pela suposição de que todo sofrimento interno está associado ou pode ser associado com alguma patologia médica. A Organização Mundial de Saúde (OMS), por exemplo, revela de maneira paradigmática o que acabamos de dizer. Em sua definição de saúde mental, ela nos diz: "saúde é um estado de completo bemestar físico, mental e social e não apenas a mera ausência de doença ou enfermidade" (OMS, 2006). Com essa definição aparentemente ampla de saúde mental, que substitui a noção de doença ou enfermidade pela noção de bem-estar, acrescentando a essa noção os adjetivos físico, mental e social, o que se faz é intensificar ainda mais a conceptualidade prévia na qual já sempre se fala sobre o sofrimento humano. Para que se tenha saúde mental propriamente dita, não é preciso apenas que não esteja mentalmente doente, no sentido mais rigoroso do termo, mas basta que se tenha qualquer perturbação do bemestar nas suas três dimensões tomadas como determinantes (física, mental e social). Com isto, ao invés de se restringir a associação entre sofrimento humano e doença, ou seja, ao invés de se estabelecer uma limitação ao predomínio do paradigma médico-psiquiátrico, o que se faz é antes elevá-lo à sua máxima potência. Tudo agora pode ser chamado de doença mental, ainda que apenas por meio da formulação negativa referente a uma falta de saúde mental.

Nós nos movemos, em suma, em um horizonte de preconceitos operativos, que não apenas encurtam nossos modos de relação com o fenômeno do sofrimento, mas que são mesmo determinantes para o modo como vemos, pensamos, nos comportamos em 
sentido amplo com esse fenômeno. A circularidade hermenêutica expressa nas estruturas prévias se confunde com aquilo que se dá a ver para nós agora em relação ao sofrimento.

Bem, mas a pergunta que resta é: é possível escapar dessas estruturas prévias, desse modo prévio de o problema do sofrimento se apresentar para nós? E, se for possível, como precisa se dar tal via de escape? Há alguma possibilidade de encontrar o sofrimento em sua gênese essencial originária, para além de todo encurtamento hermenêutico? O que significaria isso? E, por fim, por que nos relacionamos constantemente com o sofrimento por meio de um temor ante o sofrer? Será que essa posição em relação ao sofrimento é uma verdade de essência? Ou será que tem uma ligação de fundo com uma certa tradição e com os modos como essa tradição lida desde o princípio com elementos presentes no sofrimento?

Essas questões nos colocam diante de um ponto extremamente delicado, em torno do qual gira, de certa forma, um conjunto extenso de reflexões sobre as consequências de uma transformação hermenêutica da fenomenologia, expressão comumente usada para designar o movimento empreendido por Martin Heidegger já no início de seu caminho na filosofia. Em verdade, somos seres radicalmente hermenêuticos. Essa é uma posição que já vem ao nosso encontro por meio do acento diltheyano no fato de que nunca nos relacionamos com objetos pura e simplesmente por meio de representações, mas sempre já por meio de vivências, que se caracterizam justamente pelo seu nexo estrutural com a vida histórica do tempo. Não há para nós alguma coisa como uma determinação quididativa previamente dada e constituída, mas todas as nossas determinações de ser apontam para possibilidades de realização da vida histórica como um todo. Dizer isso não é estabelecer por decreto nossa essência histórica, nem declarar de imediato o vínculo com o pensamento existencial, mas seguir antes a evidência com a qual a historicidade atravessa tudo aquilo que para nós se apresenta desde o século XVIII. Não há simplesmente como escapar da historicidade, porque não há como saltar por sobre a própria sombra. A circularidade hermenêutica não é um elemento posicionado teticamente por um pensador particular ou por uma corrente de pensamento em específico, mas ela é antes o resíduo incontornável de todas as suspensões possíveis de elementos particulares capazes de interferir na pretensão de universalidade pura erguida pela tradição. Quando buscamos uma redução de tudo ao puro e a priori, o que sobra é justamente a incontornabilidade do hermenêutico. Ser um ente radicalmente hermenêutico, contudo, significa não ter nenhuma determinação ontológica prévia ao círculo, mas precisar ser a partir de apropriações específicas internas a ele. Bem, mas 
onde não há nada anterior à historicidade, não há determinações prévias de ser. Aqui reina necessariamente a indeterminação ontológica originária. É claro que é possível falar sobre propriedades físicas dos entes e mesmo sobre o corpo físico do homem. No primeiro caso, como esses entes não se constituem pelas relações que eles mesmos estabelecem, mas pelo modo como se determina o campo relacional, a historicidade não é o lugar propriamente de realização de seu ser; diz respeito antes aos seus modos de aparição. No segundo, por mais que se possa falar do corpo físico do homem, nunca se pode perder de vista a distinção estabelecida de maneira decidida por Helmut Plessner (2010) e MerleauPonty (2002) entre corpo vital e corpo físico, ou seja, nunca se pode esquecer que impera aqui sempre uma tensão entre o corpo físico e o corpo vital, entre o corpo biológico, por exemplo, um corpo que claramente depende de um horizonte hermenêutico de fixação, e o corpo fenomenologicamente experimentado. Ser um ente radicalmente hermenêutico, isto é, ser um ente marcado pela incontornabilidade de tempo e história, e, mais do que isso, ser um ente que jamais possui um simples acesso a seu ser, mas que sempre precisa conquistar seu ser em meio ao círculo hermenêutico, significa, portanto, antes de tudo, não ser senão a partir da conquista de seus modos de ser. A questão, porém, é que exatamente essa posição implode a noção moderna de sujeito e nos obriga a todos a pensar, tal como o fez pela primeira vez Martin Heidegger de maneira radical, a junção inexorável entre hermenêutica e fenomenologia.

Nós não somos seres marcados por determinações essenciais prévias. Tais determinações contradiriam por princípio a nossa radical imersão no círculo hermenêutico. Ao mesmo tempo, nós não somos simplesmente entes determinados por seus contextos relacionais. De uma maneira indireta, essa posição também contestaria a essência hermenêutica de nossas determinações de ser, porque a historicidade não seria nesse caso um traço constitutivo de nossos modos de ser, mas apenas uma espécie de filtro histórico através do qual eu me mostraria de uma maneira específica. Nós não somos entes hermenêuticos, porque nos determinamos sempre a partir de um horizonte relacional histórico, mas antes e essencialmente pelo fato de que todos os nossos modos de ser apontam para possibilidades de ser que só são concretizáveis num campo histórico específico. Não seria possível em qualquer mundo, por exemplo, estar agora diante de uma plateia falando sobre sofrimento existencial. Estar aqui, por outro lado, radicalmente me determina como quem eu sou, uma vez que meu ser se confunde com as suas determinações ônticas de ser. O que nos coloca, por outro lado, em uma junção com tal articulação radical entre determinação ontológica e possibilidades ônticas é o fato de que 
nós, originariamente, já nos encontramos sempre junto ao campo hermenêutico de realização de tais possibilidades. Não há para nós algo assim como uma interioridade previamente constituída que, a partir de suas propriedades teóricas, mentais, imaginativas ou sensíveis, se articularia com o fora. Originariamente, o que nos coloca em uma relação cooriginária com o círculo hermenêutico é justamente nossa dinâmica ekstática estrutural. Nós nunca somos primeiro dentro para depois encontrarmos o fora, nunca estamos primeiro fora do círculo para em seguida entrarmos no círculo, mas ser para nós significa abrupta e inexoravelmente já sempre se encontrar em meio à circularidade hermenêutica. Justamente tal movimento ekstático originário se confunde, por sua vez, com a compreensão fenomenológica da intencionalidade como modo de ser essencial da consciência (Husserl) primeiramente e do existir em seguida (Heidegger). Existir implica aqui já sempre se encontrar em meio aos entes, ser junto aos entes, ser jogado no mundo.

Ora, mas se não há nenhuma determinação ontológica prévia à realização de possibilidades intrínsecas ao círculo e se o existente humano se confunde inteiramente com suas possibilidades de ser em meio à circularidade hermenêutica, então se revela de maneira inequívoca o drama estrutural presente na origem mesma de todo existir. Existir significa se ver jogado abruptamente no mundo enquanto horizonte histórico de nossas possibilidades de ser. Enquanto jogado, porém, nós não temos nenhum repertório existencial capaz de tornar possível algo assim como um modo de comportamento específico. Se o que está em questão é se comportar corporalmente, não trazemos conosco nenhum modo pré-definido de determinação corporal, de tal forma que precisamos nos tornar corpos em meio ao exercício mesmo de nossa corporeidade histórica. É claro que alguém pode pensar nos movimentos reflexos como elementos de contestação de tal afirmação. É claro também que experimentos inspirados por Husserl e Merleau-Ponty revelam o quanto nosso modo de relação com os entes tem toda uma dependência de nossa compleição corporal. Se nossa cabeça não girasse, por exemplo, nós não conseguiríamos olhar para objetos senão virando todo o corpo - e isso interferiria completamente em nossos modos perceptivos. As coisas ficariam ainda piores se tivéssemos a cabeça entre as pernas ou se andássemos de cabeça para baixo. Um corpo específico sempre condiciona um modo específico de visão, de relação sensível, de apreensão, imaginação etc. De qualquer forma, é interessante lembrar que essas experiências acontecem em um mundo histórico específico e surgem em meio à discussão sobre o lugar do corpo em nossa experiência de mundo. Elas não são completamente puras e imaculadas, mas já sempre provêm de crises específicas de paradigmas e estão 
sempre voltadas para interesses e discussões que são característicos de um tempo determinado. Em suma, não contestam nossa indeterminação corporal originária. $\mathrm{O}$ mesmo vale para tudo. É difícil para nós ser um corpo, amar, escolher das coisas mais simples às mais complexas, decidir o que fazer ou não etc. E por que tudo isso é para nós sempre tão difícil? Porque simplesmente não temos nenhum modo natural de ser. Não é natural andar, respirar, dormir; não é natural amar, cantar, consumir; não é natural fazer música, poesia, filosofia; não é natural cuidar do outro ou lidar com ele com indiferença. Nada para nós é originariamente natural. Assim, a fenomenologia nos impede de pensar em padrões naturais de existir, na mesma medida em que a hermenêutica se revela como o complemento indispensável para um ente desprovido de natureza.

Assim, se não temos por nós mesmos nenhum modo de ser natural originário, o mundo enquanto horizonte histórico de manifestação dos entes em geral nos orienta e precisa nos orientar normativamente quanto aos nossos modos de ser em geral. Não que o mundo se constitua como uma espécie de senso comum, como um conjunto de opiniões e crenças compartilhadas por todos os homens em uma época. Um círculo hermenêutico, como vimos acima ao tratarmos das estruturas prévias da interpretação, é antes de tudo um campo de fenomenalização dos entes, pois é apenas nele que o fenômeno aparece enquanto fenômeno. As estruturas prévias da interpretação, estruturas estas explicitadas pela primeira vez no interior do pensamento de Heidegger na década de 1920, não determinam nossos modos de pensar os entes, na medida em que configuram nossa postura em relação a eles. Tal domínio seria um domínio restrito, uma vez que opiniões, por mais sólidas e obtusas que possam ser, são sempre sujeitas a influências as mais diversas e a alterações muitas vezes radicais. As estruturas prévias da interpretação determinam como um ente se deixa ver, como ele se dá a ver no horizonte sedimentado de seu vir a ser fenomenal, de tal modo que, quando falamos, nos comportamos, quando assumimos uma posição em relação a uma coisa ou a um estado de coisas, não somos nós e nossas idiossincrasias que decidem como os comportamentos se dão, mas os comportamentos sempre obedecem necessariamente ao modo como as coisas se apresentam no horizonte de manifestação que é o delas. Quando alguém cotidianamente, portanto, em uma situação de discussão de trabalho, vira para o seu parceiro de diálogo e diz: "você está sendo extremamente injusto comigo", é claro que ela opera tacitamente, nesse caso, com a ideia de justiça como equidade, como responsabilidade causal, como proporcionalidade. Isso, contudo, não significa de jeito algum que a pessoa tem uma concepção de justiça específica, que tornaria possível em um contexto determinado a 
utilização em um enunciado particular. No momento em que articula a noção de justiça como equidade e como o que cabe propriamente a cada um, o personagem de nosso exemplo diz o que o mundo lhe disse, de tal forma que o outro, então, compreende o dizer. Tudo isso acontece com todas as coisas, em todos os contextos, em todas as nossas possibilidades discursivas ou não. O poder do círculo hermenêutico não é um poder derivado da nossa capacidade de aplicar teoricamente conceitos oriundos de nossa tradição, mas um poder originário do próprio campo dos fenômenos. Portanto, no momento em que se questiona radicalmente o modo como um ente se mostra, esse questionamento tende de saída e na maioria das vezes a provocar uma perplexidade e uma sensação de que o outro, como disse Wittgenstein certa vez, é um louco ou um estulto. Não porque nós não conseguimos seguir seu modo de raciocínio, mas porque não conseguimos acompanhar como é que ele pode estar "vendo" o que ele "diz".

Entretanto, há ainda um outro elemento hermenêutico que é preciso levar em conta antes de responder propriamente à pergunta sobre como é possível alcançar uma liberdade em relação ao círculo hermenêutico em geral e em relação à maneira usual de ver o problema do sofrimento em particular.

O existente humano não possui nenhuma determinação ontológica originária. Dizer isso implica constatar que, caso ele simplesmente se deixasse absorver no mundo, ou seja, caso apenas entrasse no círculo hermenêutico sem travas, seria consequentemente um constructo do mundo. De maneira estranha, portanto, a indeterminação produziria um determinismo de ordem mecânico, ainda que esse determinismo tivesse raízes fenomenológicas e hermenêuticas. O que impede tal determinismo de se instaurar é o fato de que nós nunca caímos no círculo simplesmente, mas sempre caímos a partir de uma abertura de sentido que articula o campo do que propriamente acontece com cada de um de nós. Esse é um ponto extremamente importante, que precisa ser considerado com alguma calma, apesar de não podermos nos deter por demais aqui. Desde Dilthey, passouse a ver no interior da hermenêutica o mundo histórico como horizonte de sentido a partir do qual algo acontece. Se a hermenêutica já surge com Schleiermacher como uma busca do sentido, a partir do qual alguém antes de tudo constrói um discurso escrito, ela ganha com Dilthey uma inflexão histórica que a projeta para a articulação originária entre sentido e historicidade. Caso queiramos compreender o que torna possível uma determinada expressão do espírito objetivo do tempo, é preciso ter em vista o nexo estrutural de sentido entre as vivências e tal espírito objetivo. O elemento diferencial de Martin Heidegger, por sua vez, foi ter retirado a noção de sentido de um contexto mais 
amplo de articulação da ação (mundo como sentido) para pensar o vínculo ontológico entre a existência em sua indeterminação originária e em sua indeterminabilidade constitutiva como fonte propriamente dita da necessidade de sentido. Seguindo uma expressão central na década de 1920 para Heidegger, a noção de sentido de ser, o sentido é ele mesmo central na constituição do ser do fenômeno. Não porque ele determina a concreção objetiva do significado, como em Husserl (2004-2007, 2002, 1973), mas porque ele descreve o modo de ser da própria fenomenalidade. No caso do existente humano, por sua vez, como ele não tem nenhum modo prévio de determinação de sua fenomenalidade, isto é, como ele não tem ser para além do existir, não tem nenhum sentido de ser próprio, mas como é depende fundamentalmente do projeto de sentido no qual aparece. A necessidade de sentido para a ser - uma necessidade que Nietzsche já tinha diagnosticado em sua "Gaia ciência" como aquilo que vinha tornando o homem um ser cada dia mais extraordinário - provém aqui justamente da ausência originária de sentido. A questão, contudo, é que justamente essa relação entre sentido e negatividade permanece velada na experiência cotidiana do círculo hermenêutico. Dito mais expressamente, todos nós operacionalizamos simplesmente sentidos sedimentados de nosso mundo, de tal modo que nossas existências tendem constantemente a se dissipar em meio ao predomínio primário dos modos como os entes se deixam ver para nós. Para que tal predomínio seja quebrado, portanto, é preciso que o velamento da relação entre sentido e negatividade se dissolva e que a verdade da existência se desvele. Em suma, o que liberta do aprisionamento nos preconceitos historicamente determinados e assentados sobre sentidos pretensamente positivos é justamente a nadidade presente em todos os sentidos. Aqui, por sua vez, se encontra um ponto de conexão com o problema do sofrimento.

Se perguntarmos o que leva o existente humano a sofrer, a resposta não poderá ser outra senão: tudo e qualquer coisa. Os homens sofrem pelas incertezas do amor, do trabalho, da vida, na mesma medida em que sofrem por um amor sem vitalidade, por um trabalho sem entusiasmo, por uma vida insípida ainda que garantida. Eles sofrem pelas dores do corpo, na mesma medida em que um corpo sem dores não institui qualquer certeza de que não virão a sofrer. Pessoas extremamente saudáveis se deprimem, se desesperam, se entristecem. A juventude pode ser um imenso martírio para alguém que se sente incessantemente deslocado, do mesmo modo que a velhice pode ser insuportável para aquele que não consegue lidar com a perda da juventude, com as transformações do corpo, com uma nova configuração da mobilidade. A solidão assola no mesmo diapasão 
com que a ausência de solidão pode exasperar. Há quem sofra porque não tem alguém, na mesma medida em que há quem sofre por não ter jamais um espaço de recolhimento e tranquilidade. O que importa nas mil razões do sofrimento, contudo, não é tanto o fato de que há sempre uma enorme quantidade de vias que levam os homens na direção do sofrer, mas antes o fato de que as mil figuras do sofrimento possuem uma raiz evidente na constituição ontológica do ente que somos. Nossa ausência de natureza traz consigo incontornavelmente um manancial de problemas que giram em torno justamente do que institui sofrimento. Fracasso, desilusão, descontentamento, remorso, rancor, ressentimento, ilusão, engano, incompreensão etc. são todos termos que só fazem sentido para um ente desprovido de natureza. Animais não se frustram, não se iludem, não iludem, não têm remorso ou ressentimento, por mais que sofram em uma dimensão que é infinitamente mais enigmática do que a nossa. Nosso sofrimento, em suma, tem uma relação direta com aquilo que Sartre denomina em "O ser e o nada" como os lagos da negatividade e que Nietzsche detectou antes dele como o nosso sim ou não à existência. Não um sim ou não que damos em seguida à entrada na existência, mas que constitui o modo mesmo como existimos.

Bem, mas na mesma medida em que o sofrimento tem uma raiz direta em nossa indeterminação ontológica originária, ou seja, em nossa nadidade estrutural e no vínculo indelével que sempre se mantém vigente entre nadidade e sentido, boa parte da economia de nosso existir em geral se faz a partir de uma negação, de um inconformismo, de uma tergiversação e mesmo de uma revolta, de uma rebeldia, de uma insurreição contra tal nadidade e o sofrimento incontornável que sempre vem à tona com ela. Heidegger descreveu essa situação com um termo peculiar: decadência. Jogado no mundo e sem qualquer condição de por si mesmo realizar o que quer que seja, todo existente necessariamente precisa passar pela absorção na capa de preconceitos que o protege justamente de si, de seu ser, de sua indeterminação. Tal absorção aponta para uma queda mais radical na cadência do mundo e no automatismo de seus modos de interpelação. Todo existente, portanto, decai de saída e, na maioria das vezes, para Heidegger, no mundo exatamente porque só a partir de tal decadência é possível falar de familiaridade, de estabilidade, de tranquilização ontológica etc. De qualquer forma, ao colocar as coisas assim, ao pensar a absorção no mundo como uma consequência necessária de nossa indeterminação em qualquer tempo, em qualquer mundo, em qualquer campo existencial, Heidegger acaba por desconsiderar o quanto não é simplesmente indiferente em que mundo se cai, em que estruturas prévias da interpretação o fenômeno encontra a si 
mesmo. Pensando de maneira superficial, sem nenhum grande conhecimento da tradição oriental, não é possível desconsiderar o quanto o Oriente se encontra em uma outra relação com o sofrimento, com o nada, com a mortalidade e a finitude. O que nos importa agora, contudo, não é prosseguir na direção de uma análise de uma resposta histórica diversa ao sofrimento existencial. O que nos interessa é antes acompanhar o quanto as nossas narrativas do sofrimento se encontram impregnadas com uma série de elementos que nos afastam do sofrimento propriamente dito e que o maculam como necessariamente um mal.

Façamos um experimento. O que caracteriza propriamente o poder do campo fenomênico sedimentado sobre nós é justamente o fato de que os fenômenos articulam previamente as possibilidades da linguagem. Isso significa dizer ao mesmo tempo que nossos modos de fala têm raízes nos modos de aparição, assim como dependem da articulação dos sentidos pretensamente positivos disponíveis no mundo. Fenômenos sedimentados, por isso, trazem consigo narrativas sedimentadas. Como procuramos mostrar a princípio, a narrativa estruturada por nossa tradição - uma tradição que se impõe tacitamente sobre nós e que não aparece para nós senão em seus fios mais esmaecidos tende a associar sofrimento e dor tanto quanto a pensar o sofrimento a partir de noções como redenção e compaixão. Na tradição cristã, por exemplo, é clara toda uma lida melancólica em relação ao vínculo originário entre sofrimento e existência, de tal forma que boa parte da economia da vida cristã está associada com a complementação ontológica da vida em sofrimento, com a abertura de uma possibilidade de considerar o sofrimento como não sendo vão (um sofrimento que abre para a vida eterna), com a suposição de que o sofrimento por si só é sem sentido ${ }^{3}$. Assim, a identidade do homem em sofrimento tende a ser marcada pela triste identidade daquele que se vê sobrecarregado por uma moira em si mesma insuportável. Essa narrativa, que atravessa boa parte da tradição cristã e laica, tem repercussão sobre a compreensão e tratamento do sofrimento existencial. É comum, por exemplo, diante de alguém marcado por uma resposta esquizofrênica ou psicótica em uma confrontação direta com o abissal do existir, supor que essa situação é provocada pela negatividade e que, por isto, todo e qualquer acento no negativo, toda intensificação da abissalidade, toda supressão de sentidos cotidianos não poderiam trazer consigo outra coisa senão mais dissolução, mais fragmentação, mais desordem e desamparo. Como se desabrigo e desamparo tivessem necessariamente

\footnotetext{
${ }^{3}$ Picasso e a fase azul.
} 
alguma coisa em comum com estrangeiridade e desterro, diferença e nadidade, abissalidade e ausência prévia de sentidos do existir. De onde provém tal suposição? De onde provém sua obviedade? A resposta parece clara: essa suposição e sua obviedade não podem partir senão das estruturas prévias da interpretação, do modo mesmo de constituição do círculo hermenêutico em nosso mundo. Se nós suprimirmos justamente a base fornecida pelo mundo sedimentado, ou seja, pelo círculo hermenêutico no qual desde sempre nos encontramos jogados, surge imediatamente a possibilidade de inserir uma suspeita nessa obviedade e indagar radicalmente se é mesmo a nadidade, a ausência de sentido, a insegurança e a incerteza que nos levam sempre à sensação de desespero diante da totalidade. Essa justamente é a experiência, com a qual termino este texto.

Há duas metáforas relacionadas à existência que nos interessam aqui de maneira primordial: a metáfora do farol e a metáfora da ponte. Um farol em mar aberto, aparentemente frágil, imensamente firme, ereto, com uma luminosidade de lusco-fusco, oscilando em um giro regular e reiterado por toda eternidade, resistindo de maneira inusitada e franca à violência de uma ressaca e oferecendo direção e prumo ao forte leme de um barquinho genovês: eis aí algo que sempre me comoveu e que constantemente me faz pensar. O sentido do farol! Não há dúvida de que ele transcende a mera subsistência de um direcionamento, a constatação técnica de que se precisa de indicações exatas que protejam os navegantes em suas passagens ao largo dos rochedos. Orientação, direcionamento, indicações, marcas, sinais, indícios, índices, indicadores... Na superfície aparentemente plana e chã desses termos se esconde toda uma densidade própria à existência humana, aos seus riscos constitutivos, aos seus dilemas mais próprios, às suas regras e inconstâncias. Navegar, trilhar uma reta ou desviar-se de um perigo, estabelecer uma meta ou se perder sem destino, amarrar-se ao cais ou seguir em grandes circumnavegações. Mas um farol não é um lugar de plena orientação, de absoluto direcionamento. Como diz Álvaro de Campos, heterônimo de Fernando Pessoa (mais um termo peculiar, estranho - heterônimo, um nome para alguém que pode existir literalmente como um outro), no poema "Faróis": "Faróis distantes, / De luz subitamente tão acesa,/ De noite e ausência tão rapidamente volvida, /Na noite, no convés, que consequências aflitas!/ Mágoa última dos despedidos, /Ficção de pensar... Faróis distantes.../" (Pessoa, 1993). Deixando de lado as aflições e as mágoas, ressonâncias de um campo que nos importa questionar, o decisivo é o acento na noite e na ausência da luz. Se por um lado o farol fosse um ponto de luz, ele não orientaria nada. Se, por outro, ele fosse uma luz voltada em uma única direção, ele só orientaria aqueles que se 
encontrassem no feixe de sua luz. Girando em torno de si incessantemente, vivendo na tensão de luz e sombra: é assim que o farol nos orienta. Heráclito nos diz em seu fragmento 64: "O raio carrega tudo o que é" (Heraklit, 1998). O raio, uma imagem direta de Zeus e de sua temporalidade, instaura um espaço de luminosidade do qual emana um cenário e uma possibilidade de conquistar orientações. O escuro nesse cenário não é de modo algum banido, mas acolhido como parte central do acontecimento mesmo da luz. Heidegger diria: a luminosidade aqui se dá como "clareira". Existir no tempo do raio, ou seja, existir no instante como o lugar da visibilidade, nos leva justamente a colocar em questão, portanto, o quanto uma atenção propriamente dita e as possibilidades de direcionamento do existir que provêm daí não são promovidas pela fixação na luz, mas depende antes muito mais de um acompanhamento da luz na e por meio da escuridão.

A segunda metáfora que nos importa aqui é a que dá título ao presente texto: a metáfora da ponte. Uma ponte é um elemento de ligação entre duas margens, uma travessia, uma transição. Assim, tendemos a pensar a existência como sendo uma ponte estendida entre dois extremos: o nascimento e a morte. O problema, então, se apresenta como que por si mesmo. Para que a existência pudesse ser pensada como uma ponte, seria preciso, portanto, que pudéssemos fixar de maneira plena os dois extremos, que pudéssemos fixar o nascimento e a morte. No momento em que nos dispomos a empreender tal fixação, contudo, uma série de questões se levantam. Nascimento é um termo usado antes de tudo para pensar o vir a ser do homem enquanto ser biológico, enquanto vida orgânica. Assim, é ao final de um processo de maturação biológica muitas vezes interrompido e interrompível por fatores os mais diversos, que o nascimento se dá. O círculo hermenêutico, no entanto, jamais espera por nenhum processo de maturação, de desenvolvimento, de amadurecimento biológico. No momento em que, diante de uma ultrassonografia, um médico circunda a presença do embrião fecundado, não se tem jamais um ser puramente biológico. As condições de fenomenologização desse fenômeno já o arrancam radicalmente de toda e qualquer possibilidade de tal presença. É já no interior de um mundo histórico que tal presentificação ocorre. O que a medicina enquanto biologia aplicada faz, neste sentido, é, a partir de seu mundo, procurar empreender uma desmundanização do mundo, alguma coisa que aponta claramente para um dilema de Munchhausen. Isso não afeta naturalmente nada quanto à acurácia das descobertas médicas, isso não interfere em nada na capacidade de as pesquisas médicas descobrirem uma série de elementos próprios à corporeidade de um bebê. Correção não é critério de 
determinação de fenômenos originários, mas algo que antes se nutre da sedimentação de tais fenômenos.

Mas dizer isso apenas acentua o quanto não se entra por partes no círculo hermenêutico, mas já sempre nos encontramos, quando nos encontramos, em meio ao círculo. Para descrever tal fato, Heidegger, como todos sabem, usa o feliz termo "jogado" (geworfen). A palavra possui uma peculiaridade na língua alemã, porque é justamente o termo usado para descrever o nascimento dos animais. Em alemão, a vaca não dá à luz ao bezerro, mas simplesmente o joga no círculo vital - o que no caso dos bezerros não poderia ser fenomenologicamente mais adequado. Nós também somos jogados. Não na vida, mas no mundo. Não nascemos, portanto, porque não é possível fixar o existir como um processo que se inicia em um ponto determinado. O que não significa dizer que nós não caímos no ser. Se a existência é ponte, assim, ela é ponte que provém do escuro de toda proveniência.

Mas há ainda o outro extremo: a morte. Eu costumo brincar com meus alunos, ao falar sobre a noção de ser-para-a-morte em "Ser e tempo", que todo mundo, ao morrer, deve alguma coisa, não necessariamente um galo. A menção à cena da morte de Sócrates é importante para mim não pelas razões que alimentaram tantas discussões de Nietzsche a Derrida, não pela discussão sobre se o phármakon platônico seria um remédio contra a vida ou algo diverso, mas pelo caráter de incompletude que ela revela mesmo com o acontecimento da morte. A morte não fecha a existência, ela não a completa, não a termina. E isso porque, exatamente na medida em que uma existência sem futuro seria impossível, não se morre completamente imerso no presente. Ao contrário, morre-se sempre em um campo de futuro que continua ligado ao instante do fim. Exatamente isso é que Heidegger procura evidenciar por meio da distinção entre morrer (sterben) e findar (verenden).

Nós nunca findamos simplesmente, porque nunca entramos completamente no fim. Isso fica claro tanto em romances fragmentários, como o Felix Krull de Thomas Mann, que se mantiveram fragmentários porque os autores morreram em meio à escrita. Não se trata de jeito algum de um futuro indeterminado que não pôde se realizar, porque o autor morreu antes de terminar a escrita. O futuro claramente já estava aberto na escrita do romance. É por isso, por exemplo, que Thomas Mann pode, no volume que temos, apontar cenas da vida de Felix Krull, que ainda não conhecemos porque o volume não teve prosseguimento. Mas temos ainda um outro ponto. $\mathrm{O}$ importante não é apenas ter clareza quanto ao fato de que a morte não nos completa, mas também que jamais temos 
como experimentar a morte enquanto fim. Morrer significa justamente ver suprimida a possibilidade de experimentar sua morte. Neste sentido, se dependêssemos de uma experiência da morte para que pudéssemos nos pensar como mortais, a conclusão necessária seria a de que algo assim como a angústia não seria possível.

A ponte do existir, portanto, traz consigo o escuro de sua proveniência e aponta para uma margem que nunca se fixa. Uma vez mais, então, agora como ponte, a existência se revela como um espaço de sustentação (luz, solo) envolto por escuridão. Como se pode pensar, então, que se poderia lidar melhor com a existência a partir do esforço incessantemente presente por eliminar a escuridão? Será mesmo que, como Heidegger procura pensar, a existência precisa necessariamente da dimensão tranquilizadora, sedutora e alienante da decadência? Não seria possível que justamente tal desvio nos levasse justamente para o campo dos problemas existenciais? Não seria possível pensar a diferença, a nadidade, a negatividade como fonte de "saúde" existencial? Faróis de alto mar, pontes sobre o nada... É isso que se encontra exposto sem mediações no estranho quadro de Magritte "A ponte de Heráclito", com o qual termino essa exposição e essa homenagem direta a uma das vozes mais importantes dos estudos sobre Heidegger e o sofrimento humano no Brasil: Zeljko Loparic.

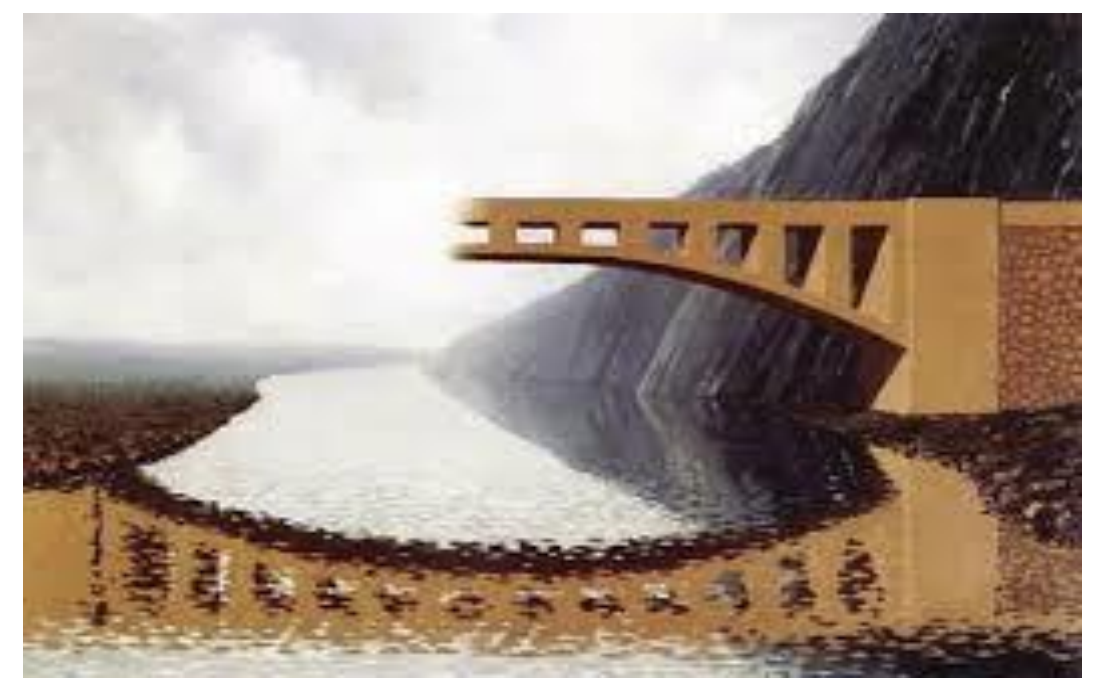

[REFERENCIA BIBLIOGRAFICA DA IMAGEM]

\section{Referências bibliográficas}


Benoist, J. [1996]. Heidegger et l'obsession de l'identité. In: Revue Philosophique de Louvain, Februar, 1996, 1, pp. 69-91.

Duarte, I.B. [2019]. Arte e técnica em Heidegger. Rio de Janeiro: Via Verita, 2019.

Bornheim, G. [2001]. Metafísica e finitude. São Paulo: Perspectiva, 2001.

Casanova, M.A.[2003]. O instante extra-ordinário: vida, história e valor na obra de Friedrich Nietzsche. Rio de Janeiro: Forense Universitária, 2003.

Casanova, M.A. [2002]. A linguagem do acontecimento apropriativo. Rev Natureza Humana, 4(2), pp. 315-43.

Casanova, M.A. [2006]. Nada a caminho: impessoalidade, niilismo e técnica no pensamento de Martin Heidegger. Rio de Janeiro: Forense Universitária, 2006.

Casanova, M.A. [2007]. Martin Heidegger und Jean-Paul Sartre: Nihilismus zwischen Seinsgeschichte und Existenzialismus. Hermeneutik Jahrbuch, Vittorio Klostermann, Frankfurt am Main, 2007.

Casanova, M.A. [2017a]. A falta que Marx nos faz: um escrito polêmico. Rio de Janeiro: Via Verita, 2017a.

Casanova, M.A. [2017b]. Existência e mundaneidade. In: Casanova, M.A. Mundo e historicidade: Leituras fenomenológicas de Ser e tempo. vol 1. Rio de Janeiro: Via Verita, 2017b.

Courtine, J.F.R. [2007]. L'Introduction à la métaphysique de Heidegger. Paris: Vrin, 2007.

Crowell, S. [2013]. Normativity and Phenomenology in Husserl and Heidegger. Cambridge: Cambridge University Press, 2013.

Heidegger, M. [1991-2002] Gesamtausgabe 1, 5, 9, 29-30, 90. Frankfurt am Main: Vittorio Klostermann, 1991-2002.

Heidegger, M. [1980]. Sobre a essência do fundamento. Porto alegre: Duas cidades, 1980.

Heidegger, M. [1989]. Ser e tempo. Petrópolis: Vozes, 1989.

Heidegger, M. [2003]. Os conceitos fundamentais da metafísica (mundo - finitude solidão). Rio de Janeiro: Forense Universitária, 2003. 
Heidegger, M. [2006]. Caminhos da floresta. Lisboa: Kalouste Gulbenkian, 2006.

Heidegger, M. [2007]. Nietzsche 1 e 2. Rio de Janeiro: Forense Universitária, 2007.

Heidegger, M. [2009]. Marcas do Caminho. Petrópolis: Vozes, 2009.

Heraklit. [1998]. Fragmente. Tübingen: Tusculum, 1998.

Husserl, E. [2002]. Werke in 8 Bände. Hamburg: Meiner, 2002.

Husserl, E. [1973]. Die Idee der Phänomenologie. Hamburg: Meiner, 1973.

Husserl, E. [2004-2007]. Investigações lógicas 1-6. Lisboa: Universidade de Lisboa, 2004-2007.

Krell, D. [1991]. Intimations of mortality. Pennsylvania: Pennsylvania University Press, 1991.

Loparic, Z. [1982]. Fenomenologia do agir em Ser e tempo. Manuscrito, 6(2), pp. 149-80, 1982.

Loparic, Z. [2003]. Sobre a responsabilidade. São Paulo: EDIPUCRS, 2003.

Loparic, Z. [2004]. Ética e finitude. São Paulo: Escuta, 2004.

Makreel, R. [1990]. The Genesis of Heidegger's Phenomenological Hermeneutics and the Rediscovered 'Aristotle Introduction' of 1922. Man and World 23, 1990, pp. $305-$ 20.

Merleau-Ponty, M. [2002]. Fenomenologia da percepção. São Paulo: Martins Fontes, 2002.

Organização Mundial de Saúde. [2006]. Constituição da Organização Mundial da Saúde. Documentos Básicos. 45ª ed. OMS, 2006.

Pessoa, F. [1993]. Álvaro de Campos: livro de versos. Lisboa: Estampa, 1993.

Plessner, H. [2010]. Die Stufen des Organischen und der Menschen (Einleitung in die philosophische Anthropologie). Berlim: De Gruyther, 2010.

Reis, R.R. [2004]. O outro fim para o Dasein: o conceito de nascimento na ontologia existencial. Rev Natureza Humana, 6(1), 2004.

Schurmann, R. [1982]. Le Principe d'Anarchie. Heidegger et la question de l’Agir. Paris: PUF, 1982. 